\title{
An I(2) Cointegration Analysis of Price and Quantity Formation in Danish Manufactured Exports
}

Nielsen, Heino Bohn

Publication date:

2001

Document version

Early version, also known as pre-print

Citation for published version (APA):

Nielsen, H. B. (2001). An I(2) Cointegration Analysis of Price and Quantity Formation in Danish Manufactured Exports. Department of Economics, University of Copenhagen. 


\section{DISCUSSION PAPERS Department of Economics University of Copenhagen}

\section{1-01}

An I(2) Cointegration Analysis of Price and Quantity Formation in Danish Manufactured Exports

Heino Bohn Nielsen

Studiestræde 6, DK-1455 Copenhagen K., Denmark Tel. +45 35323082 - Fax +45 35323000 http://www.econ.ku.dk 


\title{
An I(2) Cointegration Analysis of Price and Quantity Formation in Danish Manufactured Exports
}

\author{
Heino Bohn Nielsen* \\ Institute of Economics, University of Copenhagen \\ Studiestræede 6, DK-1455 Copenhagen K, Denmark \\ E-mail: heino.bohn.nielsen@econ.ku.dk
}

January 25, 2001

\begin{abstract}
The long-run and short-run structure of the Danish manufacturing export sector is analyzed within a cointegrated vector autoregressive model. The price variables of the analysis can be characterized as integrated of second order, I(2), but long-run homogeneity seems to cancel the $\mathrm{I}(2)$-trend allowing the analysis of a transformed data set to take place within the cointegrated I(1)-framework. Two long-run relations are found and identified as a demand-relation for Danish exports and a polynomially cointegrated price relation. In the price formation a large weight to foreign prices and an effect from the rate of inflation to the steady-state markup are found. The latter effect is interpreted as an element of caution in the price setting in an inflationary environment. To characterize the short-run behavior of the Danish export-sector a structural representation of the model is developed.
\end{abstract}

Keywords: Cointegration, I(2), Export pricing, Market-shares, Small open economy.

Jel Classification: C32, F14, F41.

\footnotetext{
${ }^{*}$ I would like to thank Hans Christian Kongsted and Dan Knudsen for many pertinent comments that significantly improved the paper. Remaining errors are of cause my own.
} 


\section{Introduction}

Since the large fluctuations of the exchange rates in the eighties there have been a considerable amount of research in the determination of foreign-trade prices and the pass-through from exchange rates to prices, see inter alia Dornbusch (1987), Hooper and Mann (1989) or Goldberg and Knetter (1997). Most of these studies have been carried out for large countries, mainly for the US, Germany and Japan, while research on the pricing behavior of exporters in small open economies is more limited. That may seem a little surprising since the characterization of a small open economy precisely involves statements on the determination of foreign trade prices.

Focus on exchange rates and prices is surely still relevant in many European countries given the large movements in both nominal and real exchange rates associated with the "currency crises" in the early nineties and following the introduction of the euro on January 1, 1999. Besides revealing information on the price-setting process per se, this line of research contributes to the understanding of the developments in trade balances and the transmission of inflation and demand shocks across countries. Moreover, exchange rates and export prices are main determinants of competitiveness on export markets and the development of export volumes plays a pronounced role for the performance of the economy. That is particularly the case for a small open economy.

This paper examines the long-run and short-run structure in the price and quantity formation of Danish manufactured exports. We thus focus the attention on a small open economy, which since the beginning of the eighties has participated in a fixed exchange rate system. The Danish export sector has previously been analyzed by inter alia Kongsted (1998b) who applies the I(1) cointegration procedure of Johansen (e.g. 1996) to a data set covering the period 1971 - 1991 and consisting of exports and the export market in volume terms, export prices, production costs and competing prices in nominal terms as well as the exchange rate. He finds the Danish export price to be determined by domestic costs and the price of imports, with weights corresponding to a pass-through from exchange rates to export prices in foreign currency of $\frac{2}{3}$.

Compared to earlier analyses of the price and quantity formation of manufactured exports the present paper generalize the statistical framework by applying a multivariate cointegration model that allows variables to be integrated up to second order, I(2), see Johansen (1992) or Rahbek, Kongsted and Jørgensen (1999). A similar model has previously been applied e.g. to the Danish import price determination in Kongsted (1998a) and to a set of American price indices in Juselius (1999). The second order stochastic trend gives the possibility of a dynamic steady-state relation for the export price where the inflation rate has a direct effect on the equilibrium markup of exporting firms. This facilitates a reinterpretation of the price-setting process in terms of uncertainty related to the inflationary process. 
The paper is organized as follows. The theoretical framework and the data are briefly presented in section 2 and section 3 outlines the statistical model. The empirical analyses of the long-run and short-run structure are presented in section 4 and 5 respectively and section 6 concludes.

\section{Theoretical Considerations and the Data}

The theoretical framework adopted here for modeling demand for exports is the traditional Armington (1969) approach. This setup specifies an inverse relationship between the export market share and the export price relative to competitors prices ${ }^{1}$

$$
x_{t}-x_{f t}=-\omega \cdot\left(p_{t}-p_{f t}-e_{t}\right), \omega>1,
$$

where $X_{t}$ and $P_{t}$ are the volume and domestic currency price of Danish manufactured exports respectively. $X_{f t}$ is the size of the export market in volume terms defined as a weighted average of imports from Denmark's trading partners. $P_{f t}$ is the competing price in foreign currency calculated as the deflator of $X_{f t}$ and $E_{t}$ is the effective exchange rate denominated as Danish kroner per foreign currency unit. The demand relation (1) can be derived from a CES utility function in the case of imperfect substitutes. Because total Danish exports is small relative to the size of the export market the constant parameter $-\omega$ can be interpreted both as the elasticity of substitution and as the price elasticity of foreign demand.

To characterize the behavior of price-setting firms, we consider a market of monopolistic competition. We assume a constant-returns-to-scale technology where the unit production costs, $C_{t}$, includes an imported component, i.e. $c_{t}=\kappa\left(p_{m t}+e_{t}\right)+$ $(1-\kappa) w_{t}$, where $\kappa=0.37$ is the import content of Danish manufactured exports, $P_{m t}$ is the price of imports in foreign currency, and $W_{t}$ is the average unit-laborcost in the manufacturing industry. Given the demand relation (1) and competitors prices, the optimal export price is set as a constant markup, $P_{t}=\frac{\omega}{\omega-1} C_{t}$, see e.g. Dixit and Stiglitz (1977) or Dornbusch (1987). In order to approximate a broader range of market structures, we follow Hung, Kim and Ohno (1993) and assume that the markup depends on competitors prices and we also include the rate of inflation. Using a log-linear approximation, the markup can be written as

$$
p_{t}-c_{t}=-\theta \cdot\left(p_{t}-p_{f t}-e_{t}\right)-\xi \cdot \Delta p_{t}, \theta \geq 0 .
$$

The pass-through from exchange rates to export prices in foreign currency is given by the partial derivative $-\frac{\partial}{\partial e_{t}}\left(p_{t}-e_{t}\right)=\frac{1-\kappa}{1+\theta}$. The special case $\theta=\kappa=0$ implies a constant markup and full exchange-rate pass-through while the limiting case $\theta \rightarrow \infty$ corresponds to the law of one price. The latter is the simple textbook assumption for a small open economy where fluctuations in the exchange rate are fully offset

\footnotetext{
${ }^{1}$ Lowercase denotes log-transformed variables.
} 
by the markup. Note that a positive import content, $\kappa>0$, implies less than full pass-through even when $\theta=0$.

Several theoretical motivations for the inflation term in (2) can be given. Haldrup (1998) presents the general case with quadratic adjustment costs. Banerjee, Cockerell and Russell (1998) give a more specific motivation for the inflation term in a markup price equation. They assume that firms have imperfect information and face a comparatively large loss if prices are set too high, e.g. due a kinked demand curve. That will cause firms to act cautiously and choose relatively low markups. Taking inflation as a measure of uncertainty a high inflation will be accompanied by a relatively low markup implying a price formation like (2) with $\xi>0$.

This theoretical setup leads to an information set given by the 6-dimensional vector $Z_{t}=\left(x_{t}, x_{f t}, p_{t}, p_{f t}, e_{t}, c_{t}\right)^{\prime}$. In the empirical analysis the sample $t=1975$ : $1, \ldots, 1996: 4$ is considered, and all data are quarterly, seasonally adjusted and logtransformed with average $1980=0$, see appendix A for further details. The data and certain linear combinations are shown in figure 1 (A)-(D). (B) shows that during the period of 1979 to 1981 the Danish krone was devalued several times, but after the commitment to the fixed exchange rate regime in 1982, the krone has generally appreciated. Figure (D) shows that up to the beginning of nineties the Danish market share, $x_{t}-x_{f t}$, and price competitiveness, $-\left(p_{t}-p_{f t}-e_{t}\right)$, are clearly positively correlated in line with the prediction of equation (1). After 1990, however, Danish manufacturers have gained considerable market shares despite a deterioration of competitiveness. A country breakdown indicates, that this export gain can be attributed mainly to the German market where the Danish market share has grown approximately 40 per cent from 1990 to 1993 in spite of a largely unchanged competitiveness, cf. (E), which illustrates the Danish market share in Germany and the Danish export price relative to the German import price in common currency. We follow Nielsen (1999) and interpret the export gain as a result of the German reunification in 1990 where Danish exporters apparently have benefited from the geographical proximity to the expanding German market, see Nielsen (1999) for a broader discussion.

Outside the German market, data do not seem to be in conflict with the theoretical model, cf. the positive correlation between the Danish market share and competitiveness on the remaining 20 markets illustrated in (F). According to (E), the reunification appears to have a long lasting effect on Danish exports and in the empirical analysis the German reunification is modeled as a permanent exogenous shift in the form of the step-dummy, D903t, equal one from $1990: 3$ onwards. Furthermore, an intervention dummy, $D 8012_{t}$, is included in the empirical analysis to account for two particularly large exchange-rate parity adjustments in September and November 1979, see appendix A for precise definitions. 

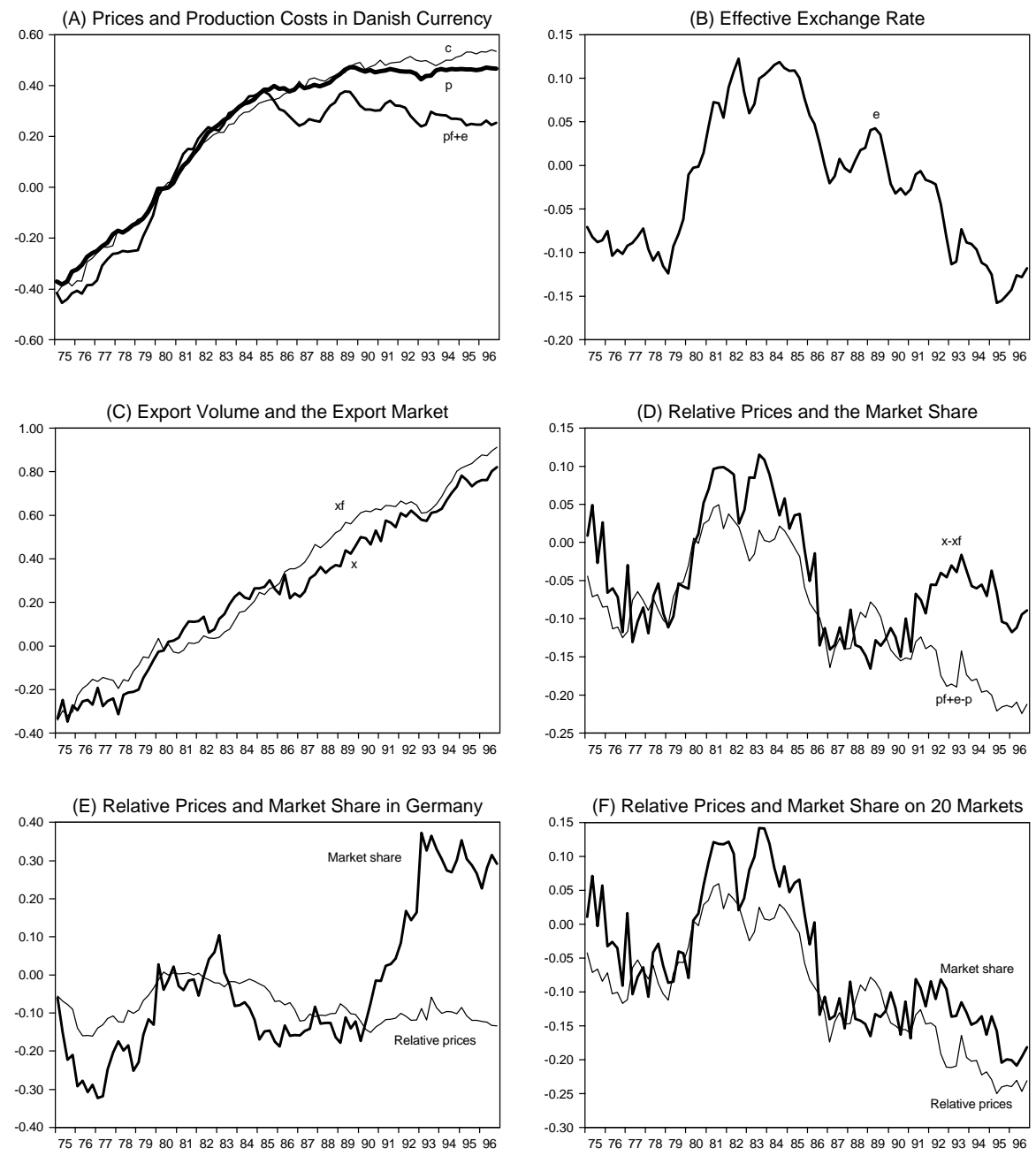

Figure 1: Data and certain linear combinations. Logs, 1980=0.

\subsection{Time Series Interpretation}

In the empirical analysis, (1) and (2) are candidates for long-run cointegrating relations and deviations from the relations should in that case be stationary.

In empirical applications it is usually assumed that the included variables are at most first-order non-stationary, I(1). In this case the inflation rate, $\Delta p_{t}$, is stationary and the parameter $\xi$ is not identified, since any linear combination of stationary variables are themselves stationary. That merely reflects that inflation has no direct long-run effect on the equilibrium markup.

Recent analyses indicate, however, that nominal variables are often better described as second-order non-stationary, I(2), see Juselius (1996 and 1999) or Kongsted (1998a) for examples. One possible scenario is the existence of one I(2) trend affecting the nominal variables, $p_{t}, p_{f t}$ and $c_{t}$, with identical coefficients, i.e. with loadings proportional to $b \equiv(0,0,1,1,0,1)^{\prime}$. This corresponds to long-run homo- 
geneity and implies that the $\mathrm{I}(2)$ trend cancels in all directions orthogonal to $b$ such that both relative prices, $p_{t}-p_{f t}-e_{t}$, and the markup, $p_{t}-c_{t}$, cointegrate from I(2) to $\mathrm{I}(1), \mathrm{CI}(2,1)$ in the notation of Engle and Granger $(1987)^{2}$. As a consequence, prices can diverge permanently but relative prices are less persistent than levels as indicated in figure 1 . If the volumes, $x_{t}$ and $x_{f t}$, and the exchange rate, $e_{t}$, are I(1), then the $\mathrm{I}(1)$ relative prices could possibly cointegrate $\mathrm{CI}(1,1)$ with the market share to form a stationary demand relation like (1). Furthermore could the $\mathrm{I}(1)$ inflation rate, $\Delta p_{t}$, cointegrate $\mathrm{CI}(1,1)$ with the relative prices and the markup through the polynomially cointegrating relationship (2) as suggested by Banerjee et al. (1998). This setup potentially identifies the parameter $\xi$ and implies a negative correlation between inflation and the markup in the steady state.

An alternative scenario could contain two I(2) trends e.g. a domestic and a foreign $\mathrm{I}(2)$ trend. In this case, it is less straightforward how stationary and economically interpretable long-run relations could be revealed from the data.

\section{The Econometric Framework}

The empirical analysis follows the general-to-specific approach of Hendry and Mizon (1993) based on a VAR model with I(1) and I(2) restrictions cf. Johansen (1996 and 1992). The basic statistical model for the $p$-dimensional data vector $Z_{t}, t=1,2, \ldots, T$, is a $\operatorname{VAR}(k)$ model that without restrictions can be parametrized to facilitate the $\mathrm{I}(2)$ analysis as

$$
\Delta^{2} Z_{t}=\Pi Z_{t-1}-\Gamma \Delta Z_{t-1}+\sum_{i=1}^{k-2} \Psi_{i} \Delta^{2} Z_{t-i}+\mu_{0}+\mu_{1} t+\Phi D_{t}+\epsilon_{t} .
$$

$\epsilon_{t}$ is assumed to be independently and identically distributed $N(0, \Omega)$ and initial values, $Z_{-k+1}, \ldots, Z_{0}$, are taken to be fixed. $\left(\Pi, \Gamma, \Psi_{1}, \Psi_{2}, \ldots, \Psi_{k-2}\right)$ are $k p \times p$ dimensional matrices of autoregressive coefficients and $\mu_{0}$ and $\mu_{1} t$ are vectors of constants and linear trend terms respectively. $D_{t}$ contains the dummy variables and $\Phi$ are corresponding coefficients.

The cointegrated I(2) model, $H_{r, s}$, is a sub-model of (3), which satisfies the following reduced rank restrictions

$$
\Pi=\alpha \beta^{\prime} \text { and } \alpha_{\perp}^{\prime} \Gamma \beta_{\perp}=\xi \eta^{\prime},
$$

where $\alpha, \beta$ are two $p \times r$ matrices of rank $r<p$ and $\xi, \eta$ are two $(p-r) \times s$ matrices of rank $s<p-r . \alpha_{\perp}$ and $\beta_{\perp}$ are orthogonal complements to $\alpha$ and $\beta$ respectively. For later use we define the matrices $\beta_{1}=\beta_{\perp}\left(\beta_{\perp}^{\prime} \beta_{\perp}\right)^{-1} \eta$ and $\beta_{2}=\beta_{\perp} \eta_{\perp}$.

The inclusion of deterministic variables in the $\mathrm{I}(2)$ model is far from straightforward. Generally they will accumulate in the non-stationary directions of the model,

\footnotetext{
${ }^{2}$ In some cases I(2) variables can cointegrate $\mathrm{CI}(2,2)$ to stationarity, see further below.
} 
and an unrestricted constant will produce a quadratic trend in the $\mathrm{I}(2)$-directions of the data. In the empirical analysis we follow Rahbek et al. (1999) and restrict the constant and the linear trend term in order to allow linear trends in all components of the model including the cointegration relations while higher order trends are excluded. The step-dummy, D903t, together with the lagged differences of the dummy are restricted in a similar way. That allows level shifts in all directions of the model but excludes the possibility of broken trends. In the case of reduced rank of $\Pi$, the model is written as

$$
\begin{aligned}
\Delta^{2} Z_{t}= & \alpha \beta^{* \prime} Z_{t-1}^{*}-\Gamma \Delta Z_{t-1}+\sum_{i=1}^{k-2} \Psi_{i} \Delta^{2} Z_{t-i} \\
& +\phi \Delta D 903_{t-1}+\sum_{i=0}^{k-2} \phi_{i} \Delta^{2} D 903_{t-i}+\mu_{0}+\theta D 8012_{t}+\epsilon_{t},
\end{aligned}
$$

where $Z_{t-1}^{*}=\left(\begin{array}{lll}Z_{t-1}^{\prime} & D 903_{t-1} & t\end{array}\right)^{\prime}$ and $\beta^{* \prime}=\left(\beta^{\prime}, \gamma_{0}^{\prime}, \beta_{0}^{\prime}\right)^{3}$.

The three mutual orthogonal matrices $\left(\beta, \beta_{1}, \beta_{2}\right)$ divide the $p$-dimensional space into directions with different properties in terms of cointegration. The $p-r-s$ dimensional matrix $\beta_{2}$ defines the loadings to the common $\mathrm{I}(2)$ trends and the linear combinations $\beta_{2}^{\prime} Z_{t}$ are $\mathrm{I}(2)$. The $r+s$ linear combinations $\left(\beta, \beta_{1}\right)^{\prime} Z_{t}$ are integrated of less than second order and thereby cointegrate. They can be further divided into $s$ directions, $\beta_{1}^{\prime} Z_{t}$, which remain $\mathrm{I}(1)$, and $r$ directions, $\beta^{\prime} Z_{t}$, which polynomially cointegrate to stationarity around a linear trend with a level shift

$$
S_{t}=\beta^{\prime} Z_{t}+\beta_{0}^{\prime} t+\gamma_{0}^{\prime} D 903_{t}-\delta \beta_{2}^{\prime} \Delta Z_{t},
$$

for some coefficient $\delta$. If $r-(p-r-s)>0$ the directions $\delta_{\perp}^{\prime} S_{t}$ will be linear combinations of the levels alone allowing for direct $\mathrm{CI}(2,2)$ cointegration from $\mathrm{I}(2)$ to trend stationarity.

The statistical analysis is performed using the two-step algorithm of Johansen (1995) but adapted to the current deterministic setup. First step is equivalent to a standard $\mathrm{I}(1)$ analysis and estimates $\left(\alpha, \beta^{*}\right)$ in a reduced rank regression with the trend and the reunification dummy restricted to the cointegration space. This defines the first step trace statistic, $Q_{r}$, for a rank of $\Pi$ equal $r$ against the unrestricted rank $p$. Similarly, second step uses reduced rank regression to estimate the parameters $\left(\xi, \eta^{*}\right)$, where $\eta^{*}$ is $\eta$ augmented with coefficients to the constant and the difference of the restricted dummy. Second step is performed conditional on the estimates from the first step and produces a trace test statistic, $Q_{r, s}$, for a rank of $\alpha_{\perp}^{\prime} \Gamma \beta_{\perp}$ equal $s$ against the unrestricted rank $p-r$. A simultaneous test for the model $H_{r, s}$ against the unrestricted alternative can be performed with the test statistic $S_{r, s}=Q_{r}+Q_{r, s}$ similar to Rahbek et al. (1999) in the case of a slightly different deterministic specification.

\footnotetext{
${ }^{3}$ Furthermore, a restriction is imposed on $\mu_{0}$ and $\phi$.
} 


\section{The Long-Run Structure}

First step of the empirical analysis is to determine the lag length, $k$, of the VAR model $(5)^{4}$. The Akaike information-criteria is minimized for a lag length of $k=3$. Likelihood-ratio tests for successive removal of lags also point towards a lag length of $k=3$ and this value is maintained in the following. The model is estimated for the effective sample of 1976:3-1996:4 and seems to have acceptable statistical properties.

\subsection{I(2) Analysis}

As presented in section 2.1 the theoretically preferred scenario is the model $H_{2,3}$. This model accommodates $r=2$ stationary relations, of which one is directly cointegrating and one is polynomially cointegrating, and $p-r-s=1 \mathrm{I}(2)$ trend.

The asymptotic critical values of the rank test, $S_{r, s}$, depend on the deterministic specification of the model, and therefore on the presence of the restricted step-dummy, $D 903_{t}$. In order to take this into account, a set of asymptotic critical values for the present model is simulated ${ }^{5}$. The test statistic, $S_{r, s}$, is reported in table 1 together with the simulated 95 per cent quantiles of the asymptotic distributions ${ }^{6}$.

The theoretically preferred model $H_{2,3}$ is not rejected against the data on a conventional 5 per cent level with a test statistic of 84.44 against a critical value of 88.00. Formally, the more restricted model $H_{1,4}$ cannot be rejected on the 5 per cent level either but is rejected on the 10 per cent level. From table 1 the choice of $p-r-s=1$ $\mathrm{I}(2)$ trend is thus relatively clear, whereas it is more uncertain whether there are $s=3$ or $s=4 \mathrm{I}(1)$ trends in the data. This reflects the generally low power of the testing procedure to discriminate between $\mathrm{I}(1)$ directions and persistent $\mathrm{I}(0)$ directions.

Further indications that the model $H_{2,3}$ is a reasonable choice are given by the eigenvalues of the companion matrix, which are the inverses of the roots of the characteristic polynomial of (5). For the model to be stationary, all eigenvalues are required to be located strictly inside the complex unit circle. Each I(1) trend in the process will entail one unit root in the polynomial whereas each $\mathrm{I}(2)$ trend will entail

\footnotetext{
${ }^{4}$ The empirical analysis is performed using the program RATS 4.20 , the procedure CATS in RATS (Hansen and Juselius, 1994) and a procedure for I(2) estimation with restricted deterministic variables written by the author (Nielsen, 2001) and the program PcFiml 9.10 (Doornik and Hendry, 1997) .

${ }^{5}$ The asymptotic critical values are simulated using the methodology of Mackinnon, Haug and Michelis (1999). Critical values at the significance level $c, q^{c}\left(T_{i}\right)$, are first simulated for the 13 different sample lengths $T_{i}=\{80,90,100,120,150,200,300,400,500,600,800,1000,1200\}$. Then the asymptotic critical value of a given test statistic, $\theta_{\infty}^{c}$, is estimated as the intercept in the response surface regression $q^{c}\left(T_{i}\right)=\theta_{\infty}^{c}+\theta_{1}^{c} T_{i}^{-1}+\theta_{2}^{c} T_{i}^{-2}+\theta_{3}^{c} T_{i}^{-3}$, where $\left\{\theta_{\infty}^{c}, \theta_{1}^{c}, \theta_{2}^{c}, \theta_{3}^{c}\right\}$ are parameters to be estimated. For all sample lengths and test statistics the simulations are performed with 10.000 replications.

${ }^{6}$ In the rank determination a model should be rejected only if all sub-models are also rejected starting from the most restricted case $H_{0,0}$, see Johansen (1996) for the same principle on the I(1) model or Rahbek et al. (1999) for an application to the I(2) model.
} 
Table 1: Test for the rank-indices of the $\mathrm{I}(2)$ model

\begin{tabular}{|c|c|c|c|c|c|c|c|}
\hline$r$ & \multicolumn{6}{|c|}{$S_{r, s}$} & $Q_{r}$ \\
\hline \multirow[t]{2}{*}{0} & 427.53 & 357.30 & 303.50 & 252.68 & 210.69 & 179.59 & 170.90 \\
\hline & 303.15 & 264.07 & 229.75 & 199.22 & 172.80 & 150.14 & 132.65 \\
\hline \multirow[t]{2}{*}{1} & & 305.40 & 236.79 & 188.85 & 148.89 & 115.65 & 111.92 \\
\hline & & 223.95 & 190.49 & 162.21 & 137.72 & 116.94 & 100.93 \\
\hline \multirow[t]{2}{*}{2} & & & 222.98 & 162.66 & 121.33 & 84.44 & 76.85 \\
\hline & & & 156.81 & 129.46 & 106.53 & 88.00 & 74.17 \\
\hline \multirow[t]{2}{*}{3} & & & & 132.64 & 86.22 & 49.72 & 44.09 \\
\hline & & & & 100.43 & 79.23 & 62.89 & 50.75 \\
\hline \multirow[t]{2}{*}{4} & & & & & 67.89 & 27.39 & 20.35 \\
\hline & & & & & 56.19 & 41.48 & 31.47 \\
\hline \multirow[t]{2}{*}{5} & & & & & & 21.37 & 9.00 \\
\hline & & & & & & 24.60 & 15.79 \\
\hline$p-r-s$ & 6 & 5 & 4 & 3 & 2 & 1 & 0 \\
\hline
\end{tabular}

Note: Italics are simulated asymptotic critical values, see note 5.

two. Given the rank indices $(r, s)$ we therefore expect to find $s+2 \cdot(p-r-s)$ unit roots in the process. The largest of the 18 eigenvalues in the unrestricted model have moduli given by

$$
(0.955,0.887,0.887,0.828,0.828,0.730,0.730,0.617),
$$

with five eigenvalues rather close one. The model $H_{2,3}$ restricts five roots to unity, and the largest eigenvalues in this restricted model have moduli given by

$$
(1,1,1,1,1,0.739,0.670,0.670,0.623,0.623) .
$$

The largest unrestricted eigenvalue of 0.739 is not particularly close to the unit circle and is practically unchanged from the unrestricted case. If we alternatively assume that all five unit roots are related to I(1) trends, corresponding to the I(1) model $H_{1,5}$, a large root of 0.949 is introduced, which clearly indicates the presence of an $\mathrm{I}(2)$ trend in data.

The eigenvalues thus seem to confirm the choice of the model $H_{2,3}$ and this model is used in the following.

\subsubsection{Feedback in the Empirical Model}

At the outset all 6 variables in $Z_{t}$ were considered endogenous for the parameters of interest. From a theoretical perspective, however, the feedback to foreign variables, $x_{f t}$ and $p_{f t}$, are expected to be weak. Production costs, $c_{t}$, are also exogenous in the theoretical setup but that is probably not the case in an open economy like Denmark where exports account for a considerable proportion of total demand. Finally, the status of the exchange rate, $e_{t}$, is ambiguous for a country participating in a fixed exchange rate mechanism, see Kongsted (1998b) for a discussion. 
Table 2: Test of no level-feedback

\begin{tabular}{|l|l|c|c|c|c|c|c|}
\hline \hline Hypothesis & $\nu$ & $x_{t}$ & $x_{f t}$ & $p_{t}$ & $p_{f t}$ & $e_{t}$ & $c_{t}$ \\
\hline$f_{i}^{\prime} \alpha=0$ & 2 & $10.68[0.005]$ & $3.18[0.204]$ & $15.55[0.000]$ & $8.31[0.016]$ & $1.44[0.488]$ & $12.30[0.002]$ \\
\hline \hline
\end{tabular}

Note: Numbers in brackets are p-values according to $\chi^{2}(\nu) . f_{i}$ are appropriately defined unit vectors.

In the I(1) model, the concept of weak exogeneity for the cointegration parameters is equivalent to no level-feedback and corresponds to zero rows in $\alpha$. In the $\mathrm{I}(2)$ model, zero rows in $\alpha$ still imply lack of feedback from the levels of $Z_{t}$ but that is not sufficient for weak exogeneity, cf. Paruolo and Rahbek (1999). For the present study, weak exogeneity is not interesting per se but it is still interesting to test the strength of the feedback from the levels of the variables. Results from these tests are reported in table 2. The null hypothesis of no level-feedback cannot be rejected for the export market, $x_{f t}$, and the exchange rate, $e_{t}$, indicating that the feedback to these variables is weak. A joint test for the hypothesis of no level-feedback to $x_{f t}$ and $e_{t}, f_{2}^{\prime} \alpha=f_{5}^{\prime} \alpha=0$, yields a test statistic of 4.73 . That corresponds to a $p$-value of 0.32 according to a $\chi^{2}(4)$ distribution. The hypothesis of no level-feedback is rejected for competitors prices, $p_{f t}$, which is a little surprising, and is clearly rejected for the domestic variables, $x_{t}, p_{t}$ and $c_{t}$.

\subsubsection{A Nominal-To-Real Transformation of the System to I(1)}

The I(1) model is still more developed than the $\mathrm{I}(2)$ model and in the following a transformation of the data will be applied that allows the analysis to continue within the simpler I(1) framework. The validity of the transformation will be tested using the sequential test proposed in Kongsted (1998a and 1999).

The theoretical candidates to long-run relations (1) and (2) are homogeneous in the price and cost variables. Homogeneity implies that the system in the long run can be written solely in the relative prices i.e. the markup, $p_{t}-c_{t}$, and the relative price in Danish currency, $p_{t}-p_{f t}-e_{t}$, together with the unrestricted exchange rate, $e_{t}$. In addition to this $\Delta p_{t}$ is included in the transformed data set in order to allow deviations from homogeneity in the short run and to give the possibility of the polynomially cointegrating relation. The proposed transformation thus results in a set of variables where the polynomially cointegrating relations in the I(2) system, $S_{t}$, correspond to ordinary I(1) cointegration relations.

The transformation requires that the hypothesis of homogeneity is accepted on all cointegrating relations $\left(\beta, \beta_{1}\right)$ i.e. that the $\mathrm{I}(2)$ trend affects the nominal variables with loadings proportional to $b$. Informally, this can be judged from the estimated loading to the $\mathrm{I}(2)$ trend

$$
\begin{aligned}
& \begin{array}{llllll}
x_{t} & x_{f t} & p_{t} & p_{f t} & e_{t} & c_{t}
\end{array} \\
& \beta_{2}^{\prime}=\left(\begin{array}{llllll}
0.38, & -0.47, & 1.00, & 0.80, & 0.85, & 0.88
\end{array}\right)
\end{aligned}
$$

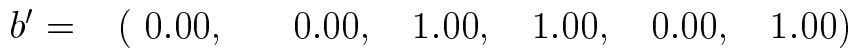


Table 3: Sequential test of long-run homogeneity

\begin{tabular}{|l|l|r|r|}
\hline \hline Hypothesis & $\nu$ & $\alpha$ unrestricted & $f_{2}^{\prime} \alpha=f_{5}^{\prime} \alpha=0$ \\
\hline$b^{\prime} \beta=0$ & 2 & $0.91[0.635]$ & $3.65[0.161]$ \\
$b^{\prime} \beta_{1}=0$ & 3 & $12.37[0.006]$ & $11.85[0.008]$ \\
\hline \hline
\end{tabular}

Note: Numbers in brackets are p-values according to $\chi^{2}(\nu)$.

The estimated coefficients to the price variables, $p_{t}, p_{f t}$ and $c_{t}$, are not far from being equal but loadings to the remaining variables are surprisingly large. Especially, the loading to the exchange rate is of the same magnitude as the price variables.

Each part of the hypothesis $b^{\prime}\left(\beta, \beta_{1}\right)=0$ can be tested separately using the sequential test of Kongsted (1998a). A significance level of $0.05 / 2$ should be applied in each step in order to obtain an overall level between $0.05 / 2$ and 0.05 . Results are reported in table 3. First step of the hypothesis, $b^{\prime} \beta=0$, implies two restrictions on $\operatorname{sp}(\beta)$ and yields a LR test statistic of 0.91 . That corresponds to a significance level of 64 per cent in a $\chi^{2}(2)$ distribution. Second step, $b^{\prime} \beta_{1}=0$, imposes three restrictions on the second step of the $\mathrm{I}(2)$ estimation procedure and is performed conditional on the restricted estimates of first step. The hypothesis yields a test statistic of 12.37, which is highly significant in a $\chi^{2}(3)$ distribution. A test for the homogeneity restriction conditional on $f_{2}^{\prime} \alpha=f_{5}^{\prime} \alpha=0$ is also reported in table 3 . The restriction $b^{\prime} \beta=0$ is still accepted albeit with a smaller $p$-value. The test statistic of the second step, $b^{\prime} \beta_{1}=0$, is lower but the $p$-value is still below the conventional $0.05 / 2 .^{7}$

The formal rejection of overall homogeneity is thus related to the $\beta_{1}$-relations, which are rarely considered in empirical analyses. The hypothesis of homogeneity is, however, a necessary condition for a model to be accepted as a reasonable representation of price-setting firms. The rejection could reflect the large loading to the exchange rate in the estimated $\beta_{2}$. The interpretation is that the $\mathrm{I}(2)$ trend is embedded in the exchange rate as well as in the nominal variables. This is somewhat surprising, as the exchange rate seems less persistent than the nominal variables, $\mathrm{cf}$. figure 1 . If $I(2)$-ness is embedded in the exchange rate this could reflect large interventions in the time series rather than the effect from a stochastic I(2) trend. In all cases, linear combinations of the nominal variables seems to cancel the $\mathrm{I}(2)$ trend, as the coefficients in $\beta_{2}$ are in the same magnitude, and the analysis of relative prices could be acceptable.

If we impose the hypothesis of no level-feedback to the export market and the exchange rate and we accept the restriction of homogeneity then the transformed I(1)

\footnotetext{
${ }^{7}$ Instead of relying on the two step estimator, which estimates $\beta$ and $\beta_{1}$ in different steps, the model could alternatively be estimated using the novel Maximum Likelihood algorithm of Johansen (1997), in which $\tau=\left(\beta, \beta_{1}\right)$ is estimated jointly. Using this estimator the hypothesis $b^{\prime} \tau=0$ is in fact accepted with a test statistic of 10.27 corresponding to a $p$-value of 7 per cent in a $\chi^{2}(5)$ distribution.
} 
model can be written as

$\Delta \widetilde{Y}_{t}=\widetilde{\alpha} \widetilde{\beta}^{* \prime}\left(\begin{array}{c}\tilde{Y}_{t-1} \\ x_{f t-1} \\ e_{t-1} \\ D 903_{t-1} \\ t\end{array}\right)+\sum_{i=1}^{2} \widetilde{\Gamma}_{i} \Delta \widetilde{Y}_{t-i}+\sum_{i=0}^{2} \widetilde{\Psi}_{i}\left(\begin{array}{c}\Delta D 903_{t-i} \\ \Delta x_{f t-i} \\ \Delta e_{t-i}\end{array}\right)+\widetilde{\mu}+\tilde{\theta} D 8012_{t}+\widetilde{\epsilon}_{t}$,

where $\tilde{Y}_{t}^{\prime}=\left(x, p-p_{f}-e, p-c, \Delta p\right)_{t}$ are the transformed endogenous variables. This model will be the maintained ${ }^{8}$.

\subsection{Identification of the Long-Run Structure}

In the light of the rejected transformation it is paramount to verify that the $\mathrm{I}(2)$ trend is not present in the transformed data. A look at the roots of the characteristic polynomial of (7) seems to indicate that the $\mathrm{I}(2)$ trend is in fact cancelled in the transformed variables. The largest eigenvalues have moduli given by

$$
(1,1,0.785,0.727,0.727,0.646,0.646,0.552) \text {, }
$$

where the largest unrestricted eigenvalue is not alarmingly close to unity. Further, a graphical inspection of the transformed variables gave no indications of $\mathrm{I}(2)$-ness and it is chosen therefore to accept the transformed system and identify the long-run structure within this framework.

The theoretical demand equation (1) is formulated as a model for the market share, $x_{t}-x_{f t}$, and an elasticity of exports with respect to foreign demand different from unity would be hard to interpret. A formal test for a unit elasticity in the long run imposes two restrictions on $s p\left(\widetilde{\beta}^{*}\right)$, and yields a LR test statistic of 6.27 . The hypothesis is thus borderline accepted with a significance value of just above 4 per cent and the restriction is imposed in the following.

The two cointegration relations will now be identified inspired from the theoretical candidates (1) and (2). As a starting point the trend and the reunification dummy will be left unrestricted. The structure (1) and (2) implies three restrictions on the first relation and two restrictions on the second and is generically identified (Johansen, 1996). Three restrictions are over-identifying and yield a LR test statistic of 6.43. The test statistic is $\chi^{2}(3)$ distributed and corresponds to a $p$-value of 9 per cent. Table 4 reports the estimated parameters under $\mathcal{H}^{1}$.

In the structure $\mathcal{H}^{1}$ the trend and the reunification dummy are insignificant in the polynomially cointegrating price relation. Restricting these terms to zero yields the results reported under $\mathcal{H}^{2}$. The additional restrictions change the LR statistic from

\footnotetext{
${ }^{8}$ In principle one observation is lost by the transformation but in the present case unused observations in the beginning of the sample can be introduced and the model (7) can be estimated for an unchanged effective sample.
} 
Table 4: Identification of the long-run relations

\begin{tabular}{|c|c|c|c|c|c|c|c|c|c|}
\hline$x_{t}-x_{f t}$ & $p_{t}-p_{f t}-e_{t}$ & $p_{t}-c_{t}$ & $\Delta p_{t}$ & $e_{t}$ & Dum903t & $t$ & $\nu$ & LR & $p$ \\
\hline \multicolumn{10}{|c|}{$\mathcal{H}^{1}$} \\
\hline 1 & $\begin{array}{c}3.101 \\
(0.392)\end{array}$ & 0 & 0 & 0 & $\begin{array}{l}-0.176 \\
(0.075)\end{array}$ & $\begin{array}{l}-0.003 \\
(0.001)\end{array}$ & 3 & 6.43 & 0.09 \\
\hline 0 & $\begin{array}{c}0.931 \\
(0.147)\end{array}$ & 1 & $\begin{array}{c}5.643 \\
(0.745)\end{array}$ & 0 & $\begin{array}{l}-0.028 \\
(0.028)\end{array}$ & $\begin{array}{c}0.000 \\
(0.001)\end{array}$ & & & \\
\hline \multicolumn{10}{|c|}{$\mathcal{H}^{2}$} \\
\hline 1 & $\begin{array}{c}3.141 \\
(0.335)\end{array}$ & 0 & 0 & 0 & $\begin{array}{l}-0.110 \\
(0.042)\end{array}$ & $\begin{array}{l}-0.004 \\
(0.001)\end{array}$ & 5 & 7.23 & 0.20 \\
\hline 0 & $\begin{array}{c}0.914 \\
(0.113)\end{array}$ & 1 & $\begin{array}{c}5.541 \\
(0.690)\end{array}$ & 0 & 0 & 0 & & & \\
\hline \multicolumn{10}{|c|}{$\mathcal{H}^{3}$} \\
\hline 1 & $\begin{array}{c}1.520 \\
(0.164)\end{array}$ & 0 & 0 & 0 & $\begin{array}{l}-0.167 \\
(0.031)\end{array}$ & $\begin{array}{c}0.000 \\
(0.001)\end{array}$ & 6 & 38.83 & 0.00 \\
\hline 0 & $\begin{array}{c}0.345 \\
(0.047)\end{array}$ & 1 & 0 & 0 & 0 & 0 & & & \\
\hline
\end{tabular}

Note: Likelihood ratio test statistics are distributed $\chi^{2}(\nu)$ and $p$ is significance level.

Italics are standard errors.

6.43 to 7.23 against two additional degrees of freedom. The structure is accepted with a total $p$-value of 20 per cent according to a $\chi^{2}(5)$ distribution.

The structure, $\mathcal{H}^{2}$, is clearly empirically identified. The long-run demand relation is given by

$$
x_{t}-x_{f t}=-3.141 \cdot\left(p_{t}-p_{f t}-e_{t}\right)+0.110 \cdot \operatorname{Dum} 903_{t}+0.004 \cdot t .
$$

The estimated price elasticity of 3.14 numerically is fairly high in an international comparison and is somewhat higher than the 2.36 found in the I(1) cointegration analysis of Kongsted (1998b). The estimated effect of the German reunification is an increase in the average Danish market share by approximately 11 per cent, which is in accordance with the impression from figure 1 (D). The trend is clearly significant, which could be a result of the applied market share restriction or some structural changes in the countries involved.

The dynamic steady-state price relation can be written as

$$
p_{t}=0.478 \cdot\left(p_{f t}+e_{t}\right)+0.522 \cdot c_{t}-2.895 \cdot \Delta p_{t} .
$$

The pass-through from exchange rates to export prices in foreign currency, calculated as the partial derivative of the long run solution to (9), is given by $-\frac{\partial}{\partial e_{t}}\left(p_{t}-e_{t}\right)=$ $\frac{1-\kappa}{1+\theta}=0.33$, implying that two-third of a competitiveness gain, induced by fluctuations in exchange rates, will be offset by an increase the markup. This indicates a significant pricing-to-market effect of Danish exporters even in the long run and is in contrast with Kongsted (1998b), who finds a simple markup on costs in Danish export pricing. One major difference between Kongsted (1998b) and the present analysis is 
Table 5: Test for misspecification of the cointegrated VAR(3)

\begin{tabular}{|l|r|r|r|}
\hline \hline \multicolumn{1}{|c|}{ Equation } & $\operatorname{AR}(1-5), F(5,56)$ & $\operatorname{Arch}(4), F(4,53)$ & Normality, $\chi^{2}(2)$ \\
\hline$\Delta\left(x_{t}-x_{f t}\right)$ & $2.421[0.05]$ & $0.234[0.92]$ & $4.193[0.12]$ \\
$\Delta\left(p_{t}-p_{f t}-e_{t}\right)$ & $0.735[0.60]$ & $0.418[0.79]$ & $0.319[0.85]$ \\
$\Delta\left(p_{t}-c_{t}\right)$ & $1.340[0.26]$ & $0.322[0.86]$ & $0.788[0.67]$ \\
$\Delta^{2} p_{t}$ & $2.351[0.05]$ & $1.422[0.24]$ & $0.517[0.77]$ \\
\hline Multivariate tests: & Normality, $\chi^{2}(8)$ & $9.823[0.28]$ \\
\multicolumn{3}{|c|}{$\mathrm{AR}(1-5), F(80,152)$} & $1.214[0.15]$ \\
\hline \hline
\end{tabular}

Note: AR is a test for autocorrelation up to 5. order. Arch tests up to 4. order.

Figures in square brackets are significance levels.

the polynomially cointegrating element. The importance of this can be evaluated by restricting the coefficient of $\Delta p_{t}$ to zero. This structure is reported under $\mathcal{H}^{3}$. The restriction results in a significantly lower weight to foreign prices and a lower price elasticity in the demand relation. These results are more similar to those in Kongsted (1998b). The restriction can, however, be safely rejected, which underlines the importance of the polynomially cointegrating element. The large coefficient to the inflation term can be interpreted as an element of caution in the price setting $\mathrm{cf}$. Bannerjee et al. (1998). The equation also implies an error correction in two steps, and the large coefficient to the inflation rate indicates a very slow adjustment, which reflects the smoothness of the time series.

An inspection of the recursively estimated eigenvalues and identified long-run parameters (not reported) indicates that the model is fairly constant. Especially, the included dummy seems to fully account for the German reunification and no instability is introduced in the model. Statistically, the model seems to be well behaved, cf. table 5 that reports a battery of misspecification tests.

\section{The Short-Run Structure}

To characterize the dynamic adjustment mechanisms in the Danish export sector we develop a structural representation of the model. A simultaneous equation model is obtained by premultiplying the reduced form with a $p \times p$ matrix $A_{0}$ of full rank. The equations has to be identified by a priori imposing 1 normalization and $p-1=3$ (linearly independent) restrictions on each equation.

Economic theory is not very precise in the description of the short-term interaction between the transformed variables in $\tilde{Y}_{t}$. We therefore rely on a combination of economic theory and empirical evidence from the reduced form in the identification 
of the system. In particular, we apply the following identification scheme

\begin{tabular}{|c|c|c|c|c|c|}
\hline Equation: & \multicolumn{4}{|c|}{$A_{0}$} & Further restrictions: \\
\hline$\Delta\left(x-x_{f}\right)_{t}$ & 1 & $-a_{12}$ & $-a_{13}$ & 0 & $\Delta(p-c)_{t-1}$ and $\Delta e_{t}$ \\
\hline$\Delta\left(p-p_{f}-e\right)_{t}$ & 0 & 1 & 0 & 0 & - \\
\hline$\Delta(p-c)_{t}$ & 0 & 0 & 1 & 0 & - \\
\hline$\Delta^{2} p_{t}$ & 0 & $-a_{42}$ & 0 & 1 & $\left(x-x^{\star}\right)_{t-1}$ \\
\hline
\end{tabular}

which fulfills the rank conditions for generic identification. The restrictions further implies strong empirically identification of the system and makes the significant parameters interpretable from economic theory.

In the market share equation we allow for a contemporaneous effect from the relative prices, $\Delta\left(p-p_{f}-e\right)_{t}$. This is a standard demand effect of a high export price and implies $a_{12}<0$. Besides this effect from the relative export prices in common currency, we expect no contemporaneous contributions from the exchange rate and exclude $\Delta e_{t}$. Further, we expect a supply effect from a high markup, but the coefficient to the lagged markup is negative in the market share equation. As the lagged markup is also significantly negative in the markup equation, we can obtain a positive contemporaneous supply effect in the market share equation via $a_{13}>0$ and by excluding $\Delta(p-c)_{t-1}$. This identification of the contemporaneous effect with the lagged stresses that the supply effect is a very short term phenomenon.

In the reduced form equation for the price acceleration, $\Delta^{2} p_{t}$, a significant positive coefficient is estimated to the lagged deviation from the long-run market share relation, $\left(x-x^{\star}\right)_{t-1}$. This has the counterintuitive effect that an increase in the demand for exports will cause firms to lower export prices, and the coefficient is therefore restricted to zero. This restriction could identify a contemporaneous effect from competitors prices with correct sign, $a_{42}<0$, as $\left(x-x^{\star}\right)_{t-1}$ is also clearly significant in the reduced form equation for relative prices. The equations for $\Delta\left(p-p_{f}-e\right)_{t}$ and $\Delta(p-c)_{t}$ are left in reduced form.

The sketched structure can be estimated with FIML and the parameters assuring identification are all significant. The system is, however, highly overparametrized and we impose 50 overidentifying restrictions to get a parsimonious system. The estimated structural equations for the market share and the price acceleration are reported in table 6 , while the reduced form equations for the competitiveness and the markup are not reported. A LR test for the 50 overidentifying restrictions yields a test statistic of 44.00, corresponding to a significance level of 71 per cent. The structural model seems to be well-specified and in particular, no structural breaks seem to occur at the time of the German reunification according to graphical inspections and formal Chow tests (not reported). 


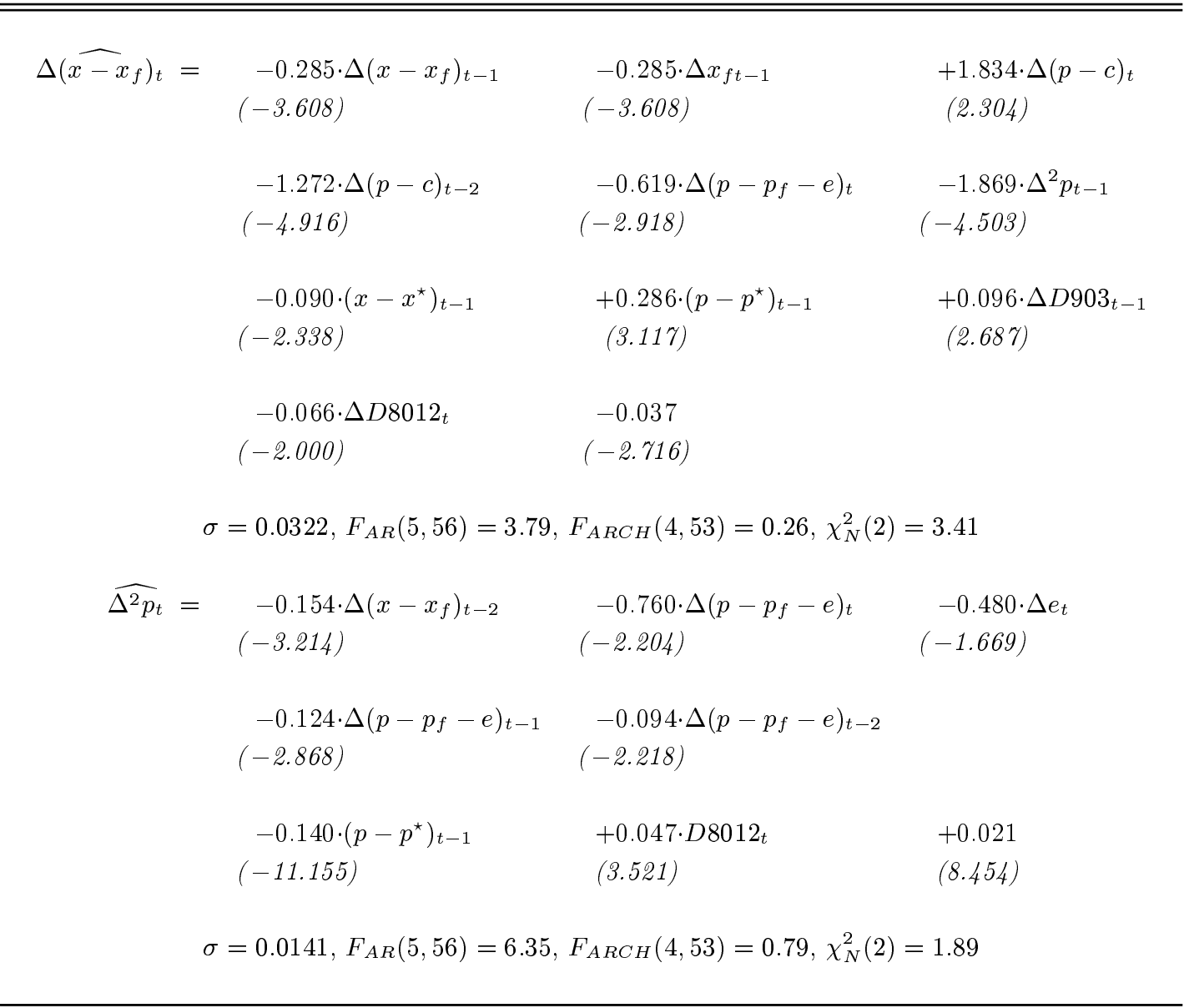

Note: Italics are t-values. $\sigma$ are standard deviations, $F_{A R}(5,56)$ are tests for autocorrelation, $F_{A R C H}(4,53)$ are tests for $A R C H$ and $\chi_{N}^{2}(2)$ are tests for normality.

\subsection{Economic Identification}

In the equation for the market share the contemporaneous change in the export market, $\Delta x_{f t}$, is excluded. This is an attractive theoretical feature as it implies that a boost on some import market ceteris paribus are equally distributed on all suppliers. The coefficients to $\Delta\left(x-x_{f}\right)_{t-1}$ and $\Delta x_{f t-1}$ are restricted to be equal such that only $\Delta x_{t-1}$ takes part in the dynamic adjustment. This restriction is accepted with a marginal significance value of 93.24 per cent.

The short-run price elasticity is estimated to -0.62 compared to a long-run price elasticity of -3.14 . A numerical elasticity below unity implies that the income effect of a change in relative prices dominates in the short run. A large proportion of the explanatory power of the equation is accounted for by the two error-correction terms. The loading to the deviation from the price equation, $\left(p-p^{\star}\right)_{t-1}$, is estimated to 0.29 and indicates a significant supply effect of a relatively high export price. In the short run, a supply effect is estimated with an elasticity of 1.83 but the effect is reduces after two quarters by a negative elasticity of -1.27 . It cannot be statistically rejected 
that these coefficients are identical, such that a high markup has a positive supply effect in only two quarters. This restrictions is, however, not imposed.

In the equation for price formation a negative coefficient of -0.76 is estimated to the contemporaneous price competitiveness, $\Delta\left(p-p_{f}-e\right)_{t}$. A change in competing prices of one per cent will thus lead to a change in the Danish export price of $\frac{\partial p_{t}}{\partial p_{f t}}=$ $\frac{0.76}{1+0.76}=0.43$ the first quarter. The effect from the exchange rate is equal to $\frac{\partial p_{t}}{\partial e_{t}}=$ $\frac{0.76-0.48}{1+0.76}=0.16$. That leads to a short-run exchange-rate pass-through from exchange rates to the export price in foreign currency of $-\frac{\partial\left(p_{t}-e_{t}\right)}{\partial e_{t}}=0.84$, to be compared to a long-run pass-through of 0.33 . Finally, a significant negative coefficient is estimated to the two quarter lagged change in the market share, $\Delta\left(x-x_{f}\right)_{t-2}$. This effect is a little hard to interpret but could act as a proxy for effects outside the VAR model. Finally, it is a little surprising that no effect is found from production costs to export prices in the short-run. One reason for this could be that in the short run it is the marginal rather than average production costs that are of importance. This could indicate that a capacity effect is suppressed in the export price formation, see also Nielsen (1999).

\section{Concluding Remarks}

In this paper, a structural econometric model for the price and quantity formation in Danish manufactured exports was identified. The results on the hypothesis of long-run homogeneity of nominal variables was somewhat mixed. The restriction was formally rejected on the $\beta_{1}$-cointegration relations from $\mathrm{I}(2)$ to $\mathrm{I}(1)$ but the subsequent analysis of the transformed system gave no indications of any remaining $\mathrm{I}(2)$ trend. In the I(1) transformed I(2) model, a long-run relation for the foreign demand for exports and a dynamic steady-state price relation were identified.

The long run price elasticity of foreign demand was estimated to 3.14 and the corresponding short run elasticity was estimated to 0.62 , implying that the income effect dominates in the short run. The effect from the German reunification on the market share was estimated to approximately 11 per cent.

The steady-state price relation was characterized by a large degree of pricing-tomarket and the weight to foreign prices implied an exchange rate pass-through of 0.33 in the long run. In the short run a somewhat higher pass-through of 0.84 was estimated. The polynomially cointegrating element from the I(2) analysis is central to the results and opens for a reinterpretation of inflation as a source of uncertainty for price-setting firms. 


\section{A Data}

The main sources of data are the International Trade and Competitiveness Indicator database from OECD and Statistics Denmark. All data are quarterly and seasonally adjusted from the source and indexed $1980=1$.

- The Danish manufactured export volume, $X_{t}$, is defined as the SITC categories 5-9 from Statistics Denmark.

- The Danish export price, $P_{t}$, is the unit-value corresponding to $X_{t}$.

- The unit production cost of Danish manufactured export, $C_{t}$, is derived as a geometrical average of the average unit-labor-cost $(U L C)$ and the import unit value in Danish currency $(P M V X)$. Both variables are taken from the econometric model Mona of the Danmarks Nationalbank (Christensen and Knudsen, 1992). Weights are taken from the input-output table of the Danish economy as 63 and 37 per cent respectively.

- The market for Danish manufactured exports, $X_{f t}$, is calculated as an arithmetic average of the import volume on 21 OECD markets with weights given from the country breakdown of Danish manufactured exports in 1989; $X_{f t}=$ $\sum_{j=1}^{21} \alpha_{j} M_{j t}$, where $M_{j t}$ and $\alpha_{j}$ are the import volume and the weight of country $j=1,2, \ldots, 21$ respectively. The export market in foreign-currency value terms is calculated as $P_{f t} X_{f t}=\sum_{j=1}^{21} \alpha_{j} P_{j t} M_{j t}$, where $P_{j t} M_{j t}$ is the import value from country $j$. Likewise, the market value in Danish currency is calculated as $E_{t} P_{f t} X_{f t}=\sum_{j=1}^{21} \alpha_{j} E_{D K . j t} P_{j t} M_{j t}$, where $E_{D K . j t}$ is the bilateral exchange rate denominated as Danish kroner per currency unit. The competing price in foreign currency is then defined as the implicit deflator of $X_{f}$, i.e. $P_{f t}=P_{f t} X_{f t} / X_{f t}$ and the implicit effective exchange rate of the Danish krone is calculated as $E_{t}=E_{t} P_{f t} X_{f t} / P_{f t} X_{f t}$.

- The dummies take the form

$$
D 903_{t}=\left\{\begin{array}{ll}
1 & \text { for } t=1990: 3-1996: 4 \\
0 & \text { elsewhere }
\end{array} \quad \text { and } D 8012_{t}=\left\{\begin{array}{cl}
1 & \text { for } 1980: 1 \\
-1 & \text { for } 1980: 2 \\
0 & \text { elsewhere }
\end{array}\right.\right.
$$




\section{References}

[1] Armington, Paul S. (1969), A Theory of Demand for Products Distinguished by Place of Production, International Monetary Fund Staff Papers, 16(1): 159-176.

[2] Banerjee, Anindya, Lynne Cockerell and Bill Russell (1998), An I(2) analysis of inflation and the markup, European University Institute Working Papers, ECO No. $98 / 26$.

[3] Christensen, Anders Møller and Dan Knudsen (1992), MONA: a quarterly model for the Danish economy, Economic Modelling, 1992(January): 10-74.

[4] Dixit, Avinash K. and Joseph E. Stiglitz (1977), Monopolistic Competition and Optimum Product Diversity, The American Economic Review, 67(4): 297-308.

[5] Doornik, Jurgen A. and David Hendry (1997), Modeling dynamic systems using Pc-Fiml 9.0 for Windows, International Thomson Publishing, London.

[6] Dornbusch, Rudiger (1987), Exchange Rates and Prices, The American Economic Review, 77(1): 93-106.

[7] Engle, Robert and Clive W. J. Granger (1987), Co-integration and error correction: representation, estimation and testing, Econometrica, 55: 251-276.

[8] Goldberg, Penelopi K. and Michael M. Knetter (1997), Goods prices and Exchange Rates: What Have We Learned?, Journal of Economic Literature, 35: 1243-1272.

[9] Haldrup, Niels (1998), A Review of the Econometric Analysis of I(2) Variables, Journal of Economic Surveys, 12: 595-650.

[10] Hansen, Henrik and Katarina Juselius (1994), Manual to Cointegration Analysis of Time Series; Cats in Rats, Estima, Evanstone.

[11] Hendry, David F. and Grayham E. Mizon (1993), Evaluating dynamic econometric models by encompassing the VAR, In Phillips, P.C.B. (ed.): Models, Methods, and Applications of Econometrics, Blackwell, Oxford.

[12] Hooper, Peter and Catherine L. Mann (1989), Exchange Rate Pass-through in the 1980s: The Case of U.S. Imports of Manufactures, Brookings Papers on Economic Activity, 1989(1): 297-337.

[13] Hung, Wansing, Yoonbai Kim and Kenichi Ohno (1993), Pricing exports: a cross-country study, Journal of International Money and Finance, 12: 3-28.

[14] Johansen, Søren (1992), A representation of vector autoregressive processes integrated of order 2, Econometric Theory, 8: 188-202. 
[15] (1995), A statistical analysis of cointegration for I(2) variables, Econometric Theory, 11: 25-59.

[16] (1996), Likelihood-based Inference in Cointegrated Autoregressive Models, 2nd ed., Oxford University Press.

[17] (1997), Likelihood Analysis of the I(2) model, Scandinavian Journal of Statistics, 24: 433-462.

[18] Juselius, Katarina (1996), A Structured VAR under Changing Monetary Policy, Journal of Business and Economic Statistics, 16: 400-412.

[19] (1999), Price Convergence in the Medium and Long Run: An I(2) Analysis of Six Price Indices, In Engle, R.F. and H. White: Cointegration, Causality, and Forecasting. A Festschrift in Honour of Clive W.J. Granger, Oxford University Press.

[20] Kongsted, Hans Christian (1998a), An I(2) Cointegration Analysis of SmallCountry Import Price Determination, Discussion Paper 98-22, Institute of Economics, University of Copenhagen.

[21] (1998b), Modelling Price and Quantity Relations for Danish Manufacturing Exports, Journal of Business and Economic Statistics, 16(1): 81-91.

[22] — (1999), Testing the Nominal-To-Real Transformation, Working Paper, Institute of Economics, University of Copenhagen.

[23] Mackinnon, James G., Alfred A. Haug and Leo Michelis (1999), Numerical Distribution Functions of Likelihood Ratio tests for Cointegration, Journal of Applied Econometrics, 14: 313-356.

[24] Nielsen, Heino Bohn (1999), Market Shares of Manufactured Exports and Competitiveness, Monetary Review, 2nd Quarter, Danmarks Nationalbank.

[25] (2001), A Toolkit for Simple and Flexible I(2) Estimation, Working Paper, Institute of Economics, University of Copenhagen.

[26] Paruolo, Paolo. and Anders Rahbek (1999), Weak Exogeneity in I(2) VAR Systems, Journal of Econometrics, 93: 281-308.

[27] Rahbek, Anders, Hans Christian Kongsted and Clara Jørgensen (1999), TrendStationarity in the I(2) Cointegration Model, Journal of Econometrics, 90: 265289. 